\title{
Editorial: Nuclear Safety Design and Innovation
}

\author{
Jun Wang ${ }^{1 *}$, Kaiyi Shi ${ }^{1}$, Zhaoming Meng ${ }^{2}$ and Shripad T. Revankar ${ }^{3}$ \\ ${ }^{1}$ Department of Engineering Physics, University of Wisconsin-Madison, Madison, WI, United States, ${ }^{2}$ College of Nuclear \\ Science and Technology, Harbin Engineering University, Harbin, China, ${ }^{3}$ Department of Nuclear Engineering, Purdue \\ University, West Lafayette, IN, United States
}

Keywords: nuclear safety, core coolant, thermal hydraulics, simulation, nuclear power plant

\section{Editorial on the Research Topic}

\section{Nuclear Safety Design and Innovation}

The electrical capacity of nuclear energy has consistently increased from the 1950s, first with development prototype reactor and ultimately installation of commercial nuclear power plants (NPPs) (BP, 2019; Budley, 2019). Since then we have had three major severe accidents despite the advances in technology and regulatory framework on the safety and security of NPPs (Budley, 2019). The Fukushima Daiichi nuclear accident has lead Japan to scale back on operations on existing NPPs. Germany has decided to phase out the NPP's operation. However, there are new constructions of NPPs in other countries and China with the fast-developing nuclear market due to the demand for clean energy. Thus nuclear safety is an important and continuing issue with NPPs. As there are new developments and innovations in nuclear safety of NPPs, many experts from different organizations are invited to share their advances in technology and innovations on nuclear reactor safety (Zhou and Zhang, 2010; Zhou et al., 2011). In this topic, many experts from different organizations are invited to share their most advanced progress and innovations.

The first part of this topic focuses on the heat transfer and bubble formation on the surface of fuel bundles. This research includes: "Diameter effect on the wall temperature behaviors during supercritical water heat transfer deterioration in circular tubes and annular channels" (Cheng et al.); "Preliminary experimental investigation on the filtration performance of submicron insoluble aerosol in a bubble column" (Li, Shi et al.); "Bubble formation characteristic of submerged singlehole orifice in aerosol suspension" (Sun et al.); "Visualized experiment of bubble behaviors in a vertical narrow rectangular channel under natural circulation condition” (Yan et al.).

The second part of this topic focuses on the heat transfer in the primary loop of a nuclear power plant and includes: "Numerical analysis of turbulent flow and heat transfer in internally finned tubes" (Liu et al.); "Startup thermal analysis of a supercritical-pressure light water-cooled reactor CSR1000" (Yuan et al.); "Effect of liquid injection arrangements on injection flow rate of a laboratory-scale venturi scrubber" (Zheng et al.); "Design of the container for the sampling and detection monitoring system of N-13 in pressurized water reactor primary loop water leakage based on the coincidence method" (Zhao et al.).

The third part of this topic talks about safety simulations and includes: "Research on timedependent failure modeling method of integrating discrete dynamic event tree with fault tree" (Xu et al.); "A numerical investigation on gaseous stratification break-up phenomenon of air fountain experiment by fountain experiment by code_sature" (Zhang C. et al.); "Sequential failure modeling and analyzing for standby redundant system based on FTA method" (Zhang M. et al.); "Analysis of categorical subgroup method for resonance self-shielding treatment" (Li S. et al.); "Study on calculation method of soluble aerosol removal efficiency under high humidity conditions" (Li, Ma et al.). 
After a few months' preparation, over 10 manuscripts were collected, to show the ongoing safety research from three different perspectives. Due to limits of time and effort, a mass of excellent work on other important aspects was not included. However, these topic are expected to provide an example to display nuclear safety research at Frontiers in Nuclear Energy. More high-quality topics

\section{REFERENCES}

BP (2019). BP Statistical Review of World Energy. BP World Energy.

Budley, B. (2019). BP Energy Outlook: 2019 Edition. London: BP p.l.c.

Zhou, S., and Zhang, X. (2010). Nuclear energy development in China: a study of opportunities and challenges. Energy 35, 4282-4288. doi: 10.1016/j.energy.2009.04.020

Zhou, Y., Rengifo, C., Chen, P., and Hinze, J. (2011). Is China ready for its nuclear expansion? Energy Policy 39, 771-781. doi: 10.1016/j.enpol.2010. 10.051 and articles are welcomed at this open platform in the future.

\section{AUTHOR CONTRIBUTIONS}

All authors listed have made a substantial, direct and intellectual contribution to the work, and approved it for publication.

Conflict of Interest: The authors declare that the research was conducted in the absence of any commercial or financial relationships that could be construed as a potential conflict of interest.

Copyright (C) 2020 Wang, Shi, Meng and Revankar. This is an open-access article distributed under the terms of the Creative Commons Attribution License (CC BY). The use, distribution or reproduction in other forums is permitted, provided the original author(s) and the copyright owner(s) are credited and that the original publication in this journal is cited, in accordance with accepted academic practice. No use, distribution or reproduction is permitted which does not comply with these terms. 